www.nature.com/leu

\title{
CORRIGENDUM
}

\section{VLA-4 affinity correlates with peripheral blood white cell count and DNA content in patients with precursor B-ALL}

AM Blenc, A Chigaev, L Sklar and RS Larson

Leukemia (2010) 24, 669; doi:10.1038/leu.2009.270

Correction to: Leukemia (2003) 3, 641-645; doi:10.1038/ sj.leu.2402827

Since the publication of this paper, the authors have noticed that one of the author's name was incorrectly listed as A Chiagev. The correct name is shown above.

The authors apologize for any inconvenience caused. 